\title{
ZATRUDNIENIE W WYBRANYCH SEKTORACH I ZAWODACH KREATYWNYCH W UNII EUROPEJSKIEJ W OKRESIE KRYZYSU GOSPODARCZEGO. SPECYFIKA I PERSPEKTYWY WZROSTU
}

\begin{abstract}
Streszczenie
W artykule przeprowadzono dynamiczną, strukturalną i komparatywną analizę zatrudnienia w wybranych zawodach i branżach reprezentujących sektor kreatywny w Unii Europejskiej w okresie poprzedzajacym globalny kryzys gospodarczy, jak i po jego nastaniu. Wskazano zagrożenia dla przyszłego wzrostu zatrudnienia w kreatywnej ekonomii, a także sformułowano rekomendacje w odniesieniu do zakresu interwencji państwa niezbędnej do pełnego wykorzystania potencjału zatrudnieniowego analizowanych sektorów w czasie wychodzenia z recesji.
\end{abstract}

Słowa kluczowe: zatrudnienie w kreatywnej gospodarce, interwencja państwa, Unia Europejska, kryzys gospodarczy

\section{EMPLOYMENT IN SELECTED ECONOMIC SECTORS AND CREATIVE OCCUPATIONS IN EUROPEAN UNION: CHARACTERISTICS AND GROWTH PROSPECTS}

\section{Summary}

The present paper offers a dynamic, structural and comparative analysis of employment in selected occupations and industries from the creative sector in the European Union, before and after the advent of the global economic crisis. Risks concerning the future employment prospects in the creative economy have been identified and recommendations on the scope of government intervention that is necessary to make full use of the employment potential of these sectors during the recovery have been formulated.

Key words: employment in creative economy, European Union, government intervention, economic crisis

\section{Wstęp}

Światowy kryzys gospodarczy, zapoczątkowany na rynkach finansowych przez upadek amerykańskiego banku Lehman Brothers we wrześniu 2008 roku, rozprzestrzenił się na całym świecie i dał się wyraźnie odczuć także w Unii Europejskiej. Nie trzeba by-

1 dr Kamil Zawadzki - Katedra Gospodarowania Zasobami Pracy, Uniwersytet Mikołaja Kopernika w Toruniu; e-mail: kamil.zawadzki@umk.pl. 
ło długo czekać na jego negatywne konsekwencje na rynkach pracy. Wskaźnik zatrudnienia osób w wieku produkcyjnym (15-64 lata) w Irlandii spadł z 69,1\% w 2007 roku do 59,2\% w 2011 roku, a w Hiszpanii odpowiednio z 65,6\% do 57,7\%. Wieloletnia tendencja wzrostu wskaźnika zatrudnienia w całej Wspólnocie zakończyła się w 2008 roku, gdy miał on swe apogeum na poziomie $65,9 \%$, po czym do 2010 roku spadł do $64,1 \%$. W UE-27 znacząco wzrosło również bezrobocie: z 7,1\% w 2008 roku do 10,5\% w 2012 roku.

Ostatnia dekada przyniosła intensyfikację badań ekonomicznych nad gospodarką kreatywna. Akcentuje się w nich przede wszystkim: wkład sektorów twórczych w powiększanie dochodu narodowego, rolę rozwoju kreatywnych metropolii oraz problematykę wyboru narzędzi polityki gospodarczej wspierającej ich działalność. Wątki dotyczące potencjału zatrudnieniowego w tych gałęziach gospodarki nie były do tej pory szerzej eksploatowane, szczególnie na tle światowego kryzysu ekonomicznego. Tę lukę ma w pewnym zakresie wypełnić niniejsze opracowanie.

Głównym celem artykułu jest strukturalna, komparatywna i dynamiczna analiza zatrudnienia w wybranych obszarach reprezentujących sektor kreatywny w Unii Europejskiej w okresie poprzedzającym kryzys gospodarczy i zaraz po jego nastaniu, a także określenie perspektyw i zagrożeń dla jego wzrostu w przyszłości. Rozważania objęły przede wszystkim lata 2008-2012, dzięki czemu opisano rozwój sektorów kreatywnych w okresie pogorszenia globalnej koniunktury. Ponadto, w artykule sformułowano listę aktualnych wyzwań i zagrożeń dla dalszego rozwoju zatrudnienia w branżach twórczych, jak również określono wynikający z nich zakres interwencji państwa, niezbędnej do pełnego wykorzystania potencjału zatrudnieniowego analizowanych sektorów w czasie wychodzenia z okresu recesji.

\section{Kwestie metodologiczne}

Analiza struktury i dynamiki zatrudnienia w kreatywnej gospodarce nie jest sprawa prosta. Pierwszym z problemów, na jakie natrafia badający, to brak jednolitych, powszechnie przyjętych definicji kreatywnej gospodarki. Kreatywną ekonomię - w zależności od akcentów - można utożsamiać z: przemysłami kultury (cultural industries), przemysłami kreatywnymi (creative industries), przemysłami praw autorskich (copyright industries), przemysłami cyfrowymi (digital industires) lub sektorami kreatywnymi (creative and knowledge-intensive sectors), [Caves, 2002; Florida, 2002; Hesmondhalgh, 2002; Howkins, 2002; Throsby, 2001; Towse, 2010; UNCTAD, 2010].

Jedną z najczęściej wykorzystywanych w literaturze definicji jest klasyfikacja oparta na kryteriach wyznaczonych przez Departament Kultury, Mediów i Sportu Wielkiej Brytanii. Według niej, są to: te przemysty, które maja swe śródto w indywidualnej kreatywności, umiejetnościach $i$ talencie, oraz które maja potencjat tworzenia wartości i miejsc pracy przę generowanie i eksploatacje własności intelektualnej [DCMS, 1998]. Zatem należą do niej: reklama, sztuki wizualne, dziedzictwo narodowe, architektura, rzemiosło artystyczne, design, przemysł filmowy, interaktywne oprogramowanie służące rozrywce (gry komputerowe), muzyka, sztuki performatywne, przemysł wydawniczy, telewizja i radio. 
Powyższe definicje mają charakter sektorowy. Jednakże w analizie kreatywnych zasobów pracy większe uzasadnienie ma ujęcie, które równolegle uwzględnia przynależność do adekwatnych sektorów (branż, gałęzi), jak i reprezentowanie zawodów kreatywnych. Przykładem takiego podejścia do mappingu kreatywnej ekonomii jest australijska koncepcja Kreatywnego trójzeba (creative trident), [Higgs, Sunningham, 2008, s. 15-18].

Zgodnie z nią, można rozróżnić trzy grupy pracowników kreatywnych (rysunek 1.):

1. Pracujacy jednocześnie w zawodzie kreatywnym i sektorze kreatywnym (na przykład tancerz w teatrze);

2. Pracujaccy w zawodach kreatywnych, ale poza sektorem kreatywnym (na przykład projektant samochodów);

3. Pracujaccy w sektorze kreatywnym, lecz nie w zawodzie kreatywnym (na przykład księgowy w wydawnictwie literackim).

RYSUNEK 1.

\section{Kreatywne zasoby pracy według koncepcji creative trident}

ZAWODY

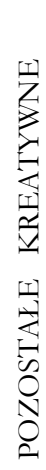

KREATYWNE

POZOSTALE

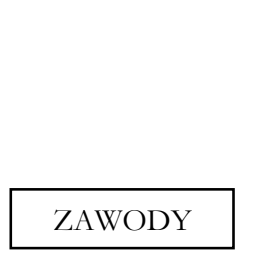

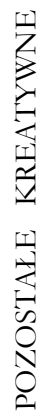

SEKTORY DZIAŁALNOŚCI

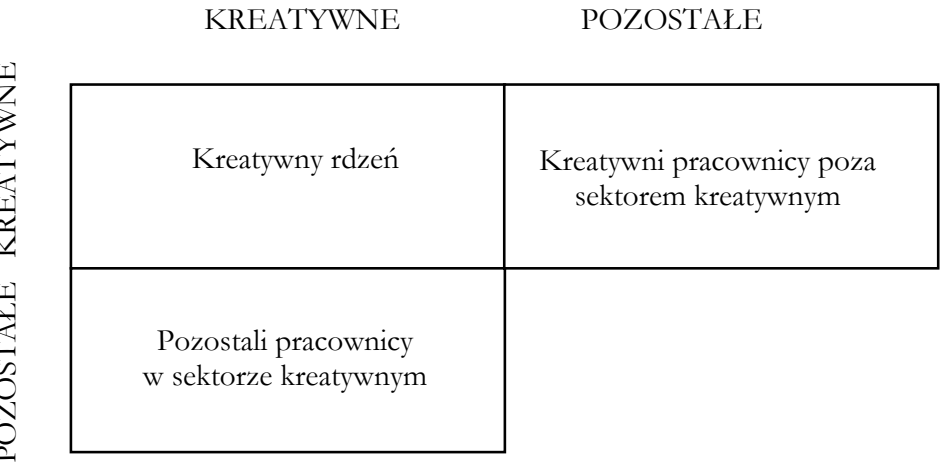

Źródło: opracowanie własne na podstawie: [Higgs, Sunningham, 2008].

Choć podejście Kreatywnego trójz̨ba wydaje się najbardziej nośne informacyjnie $\mathrm{i}$ interesujące badawczo, dokonanie analiz porównawczych między krajami europejskimi bazujących na nim nie jest jeszcze możliwe ze względu na jego bardzo wysokie wymagania co do adekwatnych - to jest wyczerpujących, porównywalnych, zdezagregowanych i ciagłych - danych statystycznych dotyczących zatrudnienia kreatywnego jednocześnie według zawodów i sektorów. Niestety, nawet posiłkując się tematycznymi danymi związanymi z przemysłami kultury publikowanymi przez Eurostat [Cultural statistics 2007 i 2011], porównanie zatrudnienia kreatywnego w okresie poprzedzającym i następującym po pojawieniu się kryzysu gospodarczego jest bardzo utrudnione z uwagi na 
zmiany w systemach klasyfikacji i zawodów, którymi się posługiwano w tym okresie 2 . Stąd w dalszej analizie empirycznej było konieczne przyjęcie osobno podejścia opartego na zawodach i osobno na branżach kreatywnych.

\section{Zatrudnienie w wybranych kreatywnych grupach zawodów w krajach Unii Europejskiej w okresie poprzedzającym i następującym po wybuchu świa- towego kryzysu gospodarczego}

Spójną międzynarodową analizę kreatywnego zatrudnienia w okresie pierwszej dekady XXI wieku można przeprowadzić na podstawie klasyfikacji zawodów ISCO-88 na przykładzie dwóch grup średnich - 243. i 245. Obie te grupy w całości można zaliczyć do zawodów sektora kreatywnego, choć - o czym trzeba pamiętać - stanowią one jedynie jego reprezentację. Grupe 243. tworza: archiwiści, bibliotekoznawcy i specjaliści informacji naukowej, a 245. - specjaliści kultury i sztuki, do których zaliczają się: literaci, dziennikarze, artyści plastycy, muzycy, tancerze, reżyserzy, producenci filmowi oraz twórcy ludowi.

WYKRES 1. Archiwiści, bibliotekoznawcy i specjaliści informacji naukowej w wybranych krajach Unii Europejskiej w latach 2004 i 2009 - ISCO-88 grupa 243. (w tys. pracujących)

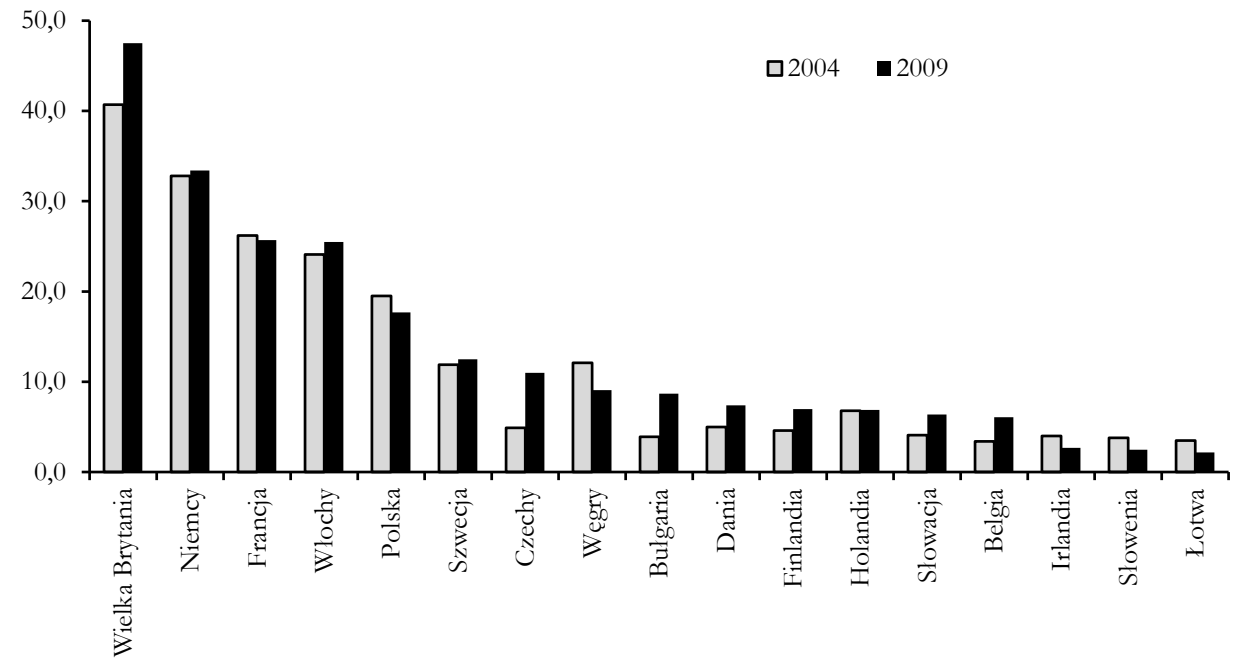

Źródło: opracowanie własne na podstawie danych bazy Eurostat: Dokument elektroniczny, tryb dostępu: [http://epp.eurostat.ec.europa.eu/portal/page/portal/employment_unemploy

2 Dane Eurostatu opublikowane w Cultural statistics w 2007 roku za 2005 rok sa agregowane według NACE 1.1 (odpowiednik PKD 2004), a klasyfikacja zawodów według ISCO-88. Z kolei, dane za 2009 rok sa już zgodne z NACE 2. (PKD 2007), a zawody od 2011 roku - z ISCO-08. 
ment_lfs/data/database?_piref616_1896469_616_925165_925165.p=h\&_piref616_189646 9_616_925165_925165.expandNode=doAction\&_piref616_1896469_616_925165_925165. nextActionId=8\&_piref616_1896469_616_925165_925165.nodePath=.EU_MAIN_TREE. data.popul.labour.employ.lfsa.lfsa_emp, data wejścia: 5.11.2013].

Zmiany liczby zatrudnionych specjalistów informacji naukowej w archiwach i bibliotekach w 2009 roku w relacji do 2004 roku w Unii Europejskiej nie były jednokierunkowe. Jednak istotne jest to, że w największych gospodarkach Wspólnoty liczba zatrudnionych w tej grupie zawodowej zwiększyła się (Wielka Brytania) lub pozostała na bardzo zbliżonym poziomie. W niektórych mniejszych krajach (Czechy, Bułgaria) nastapił wzrost ponad dwukrotny, a tam, gdzie nominalnie zatrudnienie archiwistów i bibliotekarzy spadło, spadek ten nie przekraczał jednej trzeciej (wykres 1.).

Analizując zmiany liczby zatrudnionych specjalistów archiwistyki i bibliotekoznawstwa w 2009 roku w relacji do 2004 roku w całej UE-27, należy zauważyć, że bilans zmian liczby pracujących przedstawia się dodatnio. Co istotne, wzrost liczby pracujących był o ponad 70\% większy, a w kilkunastu krajach Wspólnoty nawet kilkunastokrotnie większy w tej grupie zawodowej, niż wzrost zatrudnienia ogółem w całej Unii w latach 2004-2009 (tabela 1.).

TABELA 1.

\section{Archiwiści, bibliotekoznawcy i specjaliści informacji naukowej i zatrudnie- nie ogółem w wybranych krajach UE-27 - zmiana liczby zatrudnionych w okresie od 2009 roku do 2004 roku (\%)}

\begin{tabular}{|c|c|c|}
\hline Kraj & Archiwiści i bibliotekoznawcy & Zatrudnienie ogółem \\
\hline Czechy & 124,5 & 4,7 \\
Bułgaria & 123,1 & 11,4 \\
Belgia & 79,4 & 6,7 \\
Słowacja & 56,1 & 9,1 \\
Finlandia & 52,2 & 3,3 \\
Dania & 48,0 & 1,1 \\
Wielka Brytania & 16,7 & 1,3 \\
EU-27 & 7,9 & 4,6 \\
Włochy & 5,8 & 2,7 \\
Szwecja & 5,0 & 4,1 \\
Niemcy & 1,8 & 6,8 \\
Holandia & 1,5 & 5,4 \\
Francja & $-1,9$ & 3,4 \\
Polska & $-9,2$ & 15,7 \\
Wegry & $-24,8$ & $-3,2$ \\
Irlandia & $-32,5$ & 3,0 \\
Słowenia & $-34,2$ & 4,1 \\
Lotwa & $-37,1$ & $-3,8$ \\
\hline
\end{tabular}

Źródło: opracowanie własne na podstawie danych bazy Eurostat: Dokument elektroniczny, tryb dostępu: [http://epp.eurostat.ec.europa.eu/portal/page/portal/employment_unemploy ment_lfs/data/database?_piref616_1896469_616_925165_925165.p=h\&_piref616_189646 9_616_925165_925165.expandNode=doAction\&_piref616_1896469_616_925165_925165. nextActionId=8\&_piref616_1896469_616_925165_925165.nodePath=.EU_MAIN_TREE. data.popul.labour.employ.lfsa.lfsa_emp, data wejścia: 5.11.2013]. 
Jeszcze lepszym reprezentantem ogółu zatrudnienia w sektorze kreatywnym jest grupa 245. zawodów (m.in.: artyści, dziennikarze, twórcy). Jedynie w trzech, spośród analizowanych krajów Unii, liczba zatrudnionych w tej grupie zawodowej spadła. Na największych rynkach pracy Wspólnoty (Niemcy, Wielka Brytania, Francja, Hiszpania) zanotowano natomiast zdecydowany wzrost liczby zatrudnionych w tej grupie zawodów (wykres 2.).

WYKRES 2.

Specjaliści kultury i sztuki w wybranych krajach Unii Europejskiej w latach 2004 i 2009 - ISCO-88 grupa 245. (w tys. pracujących)

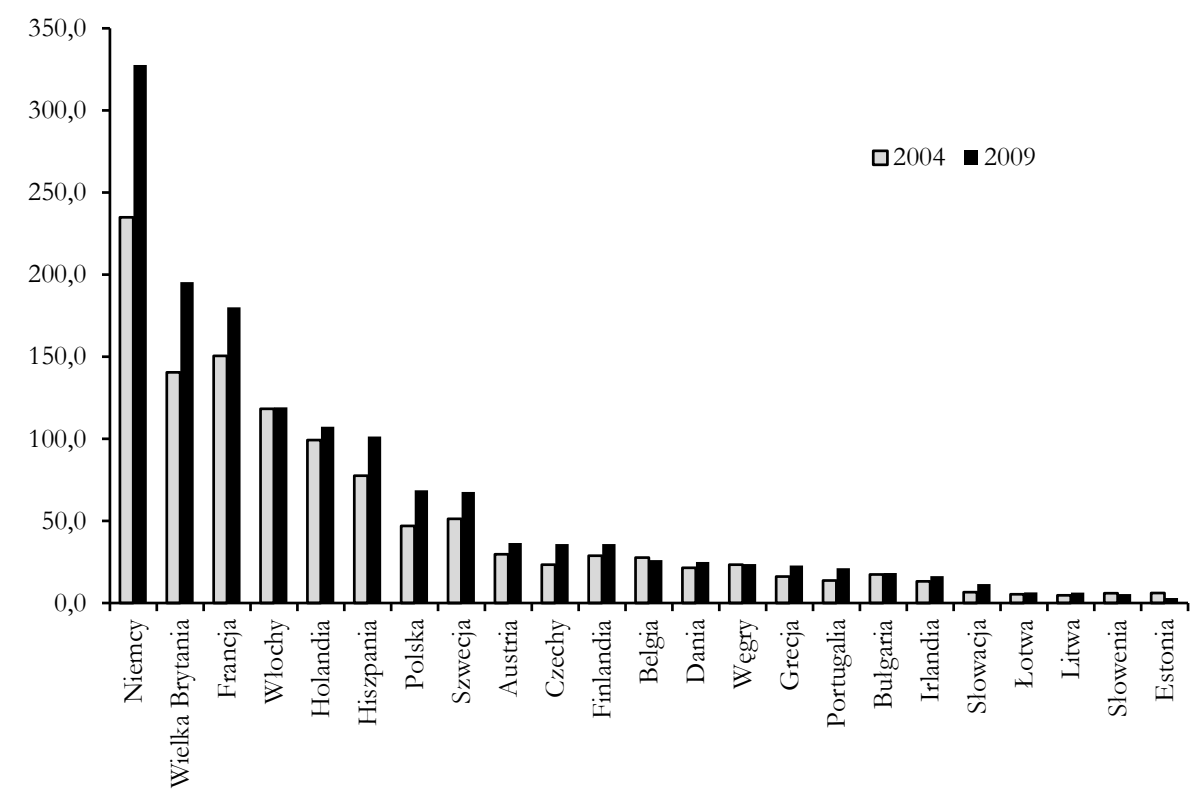

Źródło: opracowanie własne na podstawie danych bazy Eurostat: Dokument elektroniczny, tryb dostępu: [http://epp.eurostat.ec.europa.eu/portal/page/portal/employment_unemploy ment_lfs/data/database?_piref616_1896469_616_925165_925165.p=h\&_piref616_189646 9_616_925165_925165.expandNode=doAction\&_piref616_1896469_616_925165_925165. nextActionId=8\&_piref616_1896469_616_925165_925165.nodePath=.EU_MAIN_TREE. data.popul.labour.employ.lfsa.lfsa_emp, data wejścia: 5.11.2013].

Analizując dynamikę zatrudnienia specjalistów kultury i sztuki w okresie poprzedzającym nadejście kryzysu gospodarczego i zaraz po nim w całej UE-27, trzeba podkreślić, że bilans przedstawia się zdecydowanie dodatnio. Od 2004 do 2009 roku liczba pracujących w grupie 245. zawodów zwiększyła się o ponad jedną czwarta, co było niemal sześciokrotnie większym wzrostem niż wzrost zatrudnienia ogółem w całej Unii w tym czasie. Szczególnie znaczny wzrost zatrudnienia bohemy nastapił na głównych rynkach pracy Unii Europejskiej: w Niemczech i Wielkiej Brytanii o prawie 40\%, a w Hiszpanii o około 30\% (tabela 2.). 
TABELA 2.

Specjaliści kultury i sztuki i zatrudnienie ogółem w wybranych krajach UE27 - zmiana liczby zatrudnionych w 2009 roku w relacji do 2004 roku (\%)

\begin{tabular}{|l|c|c|}
\hline \multicolumn{1}{|c|}{ Kraj } & Specjaliści kultury i sztuki & Zatrudnienie ogółem \\
\hline Słowacja & 74,6 & 9,1 \\
Portugalia & 55,5 & $-1,5$ \\
Czechy & 53,8 & 4,7 \\
Polska & 46,4 & 15,7 \\
Grecja & 41,4 & 4,4 \\
Niemcy & 39,5 & 6,8 \\
Wielka Brytania & 39,2 & 1,3 \\
Litwa & 38,3 & $-1,8$ \\
Szwecja & 32,0 & 4,1 \\
Hiszpania & 30,8 & 4,9 \\
EU-27 & 27,1 & 4,6 \\
Irlandia & 25,0 & 3,0 \\
Finlandia & 25,0 & 3,3 \\
Austria & 23,6 & 7,7 \\
Lotwa & 22,2 & $-3,8$ \\
Francja & 19,7 & 3,4 \\
Dania & 16,7 & 1,1 \\
Holandia & 8,3 & 5,4 \\
Bułgaria & 5,7 & 11,4 \\
Wegry & 1,7 & $-3,2$ \\
Włochy & 0,8 & 2,7 \\
Belgia & $-5,1$ & 6,7 \\
Słowenia & $-6,7$ & 4,1 \\
Estonia & $-47,5$ & 0,4 \\
\hline
\end{tabular}

Źródło: opracowanie własne na podstawie danych bazy Eurostat: Dokument elektroniczny, tryb dostępu: [http://epp.eurostat.ec.europa.eu/portal/page/portal/employment_unemploy ment_lfs/data/database?_piref616_1896469_616_925165_925165.p=h\&_piref616_189646 9_616_925165_925165.expandNode=doAction\&_piref616_1896469_616_925165_925165. nextActionId=8\&_piref616_1896469_616_925165_925165.nodePath=.EU_MAIN_TREE. data.popul.labour.employ.lfsa.lfsa_emp, data wejścia: 5.11.2013].

\section{Charakterystyka zatrudnienia w kreatywnych sektorach w Unii Europejskiej po nastaniu kryzysu gospodarczego}

Analizę sektorową zatrudnienia w branżach kreatywnych w okresie kryzysu gospodarczego można przeprowadzić na podstawie danych dotyczących następujących działów Statystycznej Klasyfikacji Działalności Gospodarczej we Wspólnocie Europejskiej (NACE rev. 2):

- 58 - działalność wydawnicza;

- 59 - działalność związana z produkcja: filmów, nagrań wideo, programów telewizyjnych, nagrań dźwiękowych i muzycznych;

- 60 - nadawanie programów ogólnodostępnych i abonamentowych; 
- 90 - działalność twórcza związana z kulturą i rozrywka, oraz

- 91 - działalność bibliotek, archiwów, muzeów i pozostała działalność związana z kultura.

Podobnie jak w przypadku analizy opartej na zawodach, tak i to zestawienie jest jedynie reprezentacją sektora kreatywnego. Powyższe pięć kodów działalności obejmuje te działy, które na poziomie dwóch cyfr kodowania NACE w całości wchodzą w skład branży kreatywnej. Dołączenie kolejnych grup, choć uzasadnione merytorycznie, wymagałoby dysponowania porównywalnymi w skali europejskiej danymi na niższym poziomie agregacji (minimum czterech cyfr).

W 2009 roku, kiedy ogólnoświatowy kryzys gospodarczy uwidocznił się już wyraźnie, łączne zatrudnienie w powyższych pięciu działach w UE-27 w 2009 roku szacowano na 3,6 mln osób, co stanowiło około 1,7\% zatrudnienia ogółem w całej Wspólnocie w tym roku $^{3}$. Największy udział zatrudnienia w sektorach kreatywnych w zatrudnieniu ogółem zanotowano w krajach nordyckich, a najniższy w Portugalii i Rumunii. Jeśli chodzi o strukturę zatrudnienia w sektorach kreatywnych w Unii Europejskiej, według płci, warto zaznaczyć, że w większości krajów udział kobiet w zatrudnieniu kreatywnym był wyższy (choć zwykle nieznacznie) niż w zatrudnieniu ogółem. Pracownicy sektorów kreatywnych są - co jest powszechną zasadą - dobrze wykształceni. We wszystkich krajach UE-27 udział zatrudnionych w sektorach kreatywnych, mających wykształcenie wyższe, znacznie przekraczał udział tych osób w zatrudnieniu ogółem. Dla całej Unii Europejskiej łącznie różnica ta wyniosła aż 24 punkty procentowe.

Charakterystyczną cechą sektorów kreatywnych Europy jest powszechność występowania nietypowych form zatrudnienia i czasu pracy. W niektórych krajach (Włochy, Holandia, Irlandia i Austria) samozatrudnieni wraz z pomagającymi członkami rodziny w 2009 roku stanowili ponad 30\% pracujących w sektorach kreatywnych, podczas gdy w zatrudnieniu ogółem znacznie mniejszy odsetek. Zatrudnienie na czas określony występuje wyraźnie częściej w sektorze kreatywnym niż w zatrudnieniu ogółem, m.in.: we Francji, Danii, Słowenii i Belgii, a rzadziej w Polsce, Holandii i Włoszech. Niemal w całej Europie zatrudnienie w niepełnym wymiarze pojawia się częściej w sektorze kreatywnym niż w ogóle zatrudnienia; dla UE-27 jest to odpowiednio: 25\% i 19\%. Powszechnym wyróżnikiem zatrudnienia w sektorach kreatywnych jest ponadto częstsze wykonywanie pracy w domu oraz praca jednocześnie u kilku pracodawców.

Należy podkreślić, że w 2009 roku omawianych pięć sektorów kreatywnych w całej UE-27 dawało zatrudnienie zaledwie dwom trzecim pracowników zatrudnionych w zawodach kreatywnego rdzenia (chodzi o grupę specjalistów kultury i sztuki). Jednak wystapiły znaczne różnice w poszczególnych krajach: o ile w Belgii i Szwecji sektory kreatywne zatrudniały poniżej połowy reprezentantów grupy 245. zawodów, to w: Polsce, Estonii, Litwie i Słowenii około 80\%. Wskazuje to, jak silnie może być niedoszacowana skala zatrudnienia kreatywnego, gdy, ze względu na brak dostępu do porównywalnych danych zagregowanych na odpowiednim poziomie, ogranicza się analizę wyłącznie do danych sektorowych, a pomija reprezentantów kreatywnej klasy pracujących poza sektorami uznanymi za kreatywne.

\footnotetext{
${ }^{3}$ Analiza na podstawie danych Eurostat.
} 


\section{Dynamika zatrudnienia w kreatywnych sektorach w Unii Europejskiej w latach 2008-20124}

Analizę dynamiki zatrudnienia w sektorach kreatywnych w okresie pierwszych lat trwania globalnego kryzysu gospodarczego można przeprowadzić rozpatrując pięć, przywoływanych, działów klasyfikacji NACE rev. 2., które na poziomie kodów dwucyfrowych w całości wchodzą w skład branży kreatywnej (tabela 3.).

TABELA 3. Dynamika liczby zatrudnionych w wieku 15-64 lata w UE-27, w latach 2008-2012, w gospodarce ogółem i według wybranych działów kreatywnych

\begin{tabular}{|c|c|c|c|c|c|c|}
\hline \multirow[t]{2}{*}{ Wyszczególnienie } & \multicolumn{4}{|c|}{ Zmiana do roku poprzedniego (\%) } & \multirow{2}{*}{$\begin{array}{c}\text { Zmiana } 2012 \\
\text { do } 2008(\%)\end{array}$} & \multirow{2}{*}{$\begin{array}{c}\text { Zmiana } 2012 \\
\text { do } 2009(\%)\end{array}$} \\
\hline & 2009 & 2010 & 2011 & 2012 & & \\
\hline Ogółem & $-1,8$ & $-0,8$ & 0,2 & $-0,3$ & $-2,6$ & $-0,9$ \\
\hline NACE 58 & $-1,1$ & $-2,4$ & $-5,0$ & 2,1 & $-6,4$ & $-5,3$ \\
\hline NACE 59 & $-6,0$ & 4,9 & 8,2 & $-1,5$ & 5,1 & 11,8 \\
\hline NACE 60 & 15,1 & $-0,6$ & $-2,4$ & 0,6 & 12,3 & $-2,5$ \\
\hline NACE 90 & 1,5 & $-0,9$ & $-1,6$ & 4,6 & 3,6 & 2,0 \\
\hline NACE 91 & $-0,6$ & $-1,5$ & 2,4 & $-0,6$ & $-0,3$ & 0,3 \\
\hline Kreatywne łącznie & 0,5 & $-0,8$ & $-1,0$ & 1,8 & 0,4 & $-0,1$ \\
\hline
\end{tabular}

Źródło: opracowanie własne na podstawie danych bazy Eurostat: Dokument elektroniczny, tryb dostępu: [http://epp.eurostat.ec.europa.eu/portal/page/portal/employment_unemploy ment_lfs/data/database?_piref616_1896469_616_925165_925165.p=h\&_piref616_189646 9_616_925165_925165.expandNode=doAction\&_piref616_1896469_616_925165_925165. nextActionId=8\&_piref616_1896469_616_925165_925165.nodePath=.EU_MAIN_TREE. data.popul.labour.employ.lfsa.lfsa_emp, data wejścia: 5.11.2013].

Analizując zmiany zatrudnienia w całej gospodarce ówczesnej Unii Europejskiej, można zauważyć, że poza rokiem 2011, w którym nastapiła nieznaczna poprawa, od 2008 do 2012 roku zatrudnienie spadło (łącznie o 2,8\%). Największa redukcja liczby osób pracujących w gospodarce ogółem miała miejsce między 2008 a 2009 rokiem, gdy ubyło ich niemal 2\%. Na tym tle zmiana wolumenu zatrudnionych w pięciu działach kreatywnych łącznie wypadła lepiej, choć należy podkreślić, że nie znacząco lepiej i różnie w rozmaitych sektorach analizowanej branży. Największy spadek rok do roku odnotowano w 2011 roku, w którym ubył 1\% zasobów osób pracujących w pięciu działach kreatywnych łącznie w porównaniu z rokiem poprzednim. Rok 2012 przyniósł już wyraźną poprawę liczby pracujących w sektorach kreatywnych, gdy zatrudnionych tam było 0,4\% osób więcej niż w 2008 roku i 1,8\% więcej niż w 2011 roku.

Najgorsze wyniki pod względem dynamiki zatrudnienia miała w badanym okresie branża wydawnicza, w której w 2012 roku pracowało o ponad 78 tys. osób mniej niż w 2008 roku. Trudno oceniać, na ile zjawisko to ma charakter restrukturyzacyjny, wynikający z przemian w funkcjonowaniu branży, rozwoju mediów elektronicznych i prze-

${ }^{4}$ Porównywalne roczne dane sektorowe według klasyfikacji NACE rev. 2 są dostępne jedynie za okres 2008-2012. 
mian w stylu konsumpcji dóbr kultury, a na ile jest efektem spadku popytu na dobra wyższego rzędu będącego pochodna kryzysu gospodarczego. Pozostałe cztery działy sektora kreatywnego radzily sobie lepiej i - poza działem 91. (biblioteki, archiwa, muzea, pozostała działalność kulturalna) - zatrudnienie w nich między 2008 rokiem a 2012 rokiem wzrosło. W działalności twórczej związanej z kulturą i rozrywką w tym czasie przybyło 35 tys. pracujaccych, a w działalności obejmującej produkcję multimediów - prawie 22 tys. pracujących. Z pewną ostrożnością należy patrzeć na wyniki dotyczące zatrudnienia w branży nadawczej. Jej świetny wynik ogółem w latach 2008-2012 (przyrost pracujących o 12,3\%) był spowodowany głównie skokowym wzrostem zatrudnionych w 2009 roku, po którym branża ta radziła sobie gorzej (2,5\% spadek liczby pracujących w 2012 w porównaniu z 2009 rokiem ) niż gospodarka ogółem $(0,9 \%$ spadek w tym samym okresie).

\section{Aktualne wyzwania dla dalszego rozwoju zatrudnienia w kreatywnej gospodarce w Unii Europejskiej}

Przeprowadzone analizy zmian zatrudnienia w zawodach i branżach kreatywnych ukazują, że sektory kreatywne - szczególnie produkcja treści multimedialnych oraz działalność związana z kulturą i rozrywką - charakteryzują się wyraźnym potencjałem kreowania (lub przynajmniej utrzymywania) miejsc pracy, także w okresie recesji lub spowolnienia gospodarczego. Tym niemniej, aby w najbliższych latach wychodzenia z czasu dekoniunktury możliwości tworzenia tam miejsc pracy wykorzystać w pełni, należy mieć świadomość specyfiki funkcjonowania tego sektora i wynikających z niej zagrożeń.

Po pierwsze, sektory kreatywne w dużej mierze cierpią na niewystarczający dostęp do kapitału na rozwój. Branże ze znacznym udziałem sektora publicznego są uzależnione w dużym stopniu od aktualnej kondycji narodowych budżetów, ich perspektywy rozwoju, a więc są silnie zdeterminowane bieżącą sytuacją makroekonomiczną danego kraju. Z kolei, dla reprezentantów kreatywnego sektora prywatnego problemem staje się niska rozpoznawalność potencjału wzrostowego branży wśród instytucji finansowych, co skutkuje ograniczonym dostępem do kredytów.

Kolejnym elementem, mogącym stać się przeszkodą rozwojowa, jest sektorowość prowadzenia polityki i ustawodawstwa na szczeblu centralnym. Pełne wykorzystanie potencjału kreatywnej gospodarki wymaga współpracy resortów: kultury i dziedzictwa narodowego, gospodarki, sportu i turystyki, nauki i szkolnictwa wyższego, rozwoju regionalnego i innych. Programy realizowane w ramach jednego obszaru mogą okazać się niewystarczające, a spory międzyresortowe $\mathrm{w}$ projektach interdyscyplinarnych uniemożliwiać ich realizację i wdrożenie stosownych uregulowań prawnych.

$\mathrm{Na}$ rynek pracy kreatywnej gospodarki nie można patrzeć tylko przez pryzmat strony popytowej. Zbyt niska podaż wysoko wykwalifikowanych pracowników będzie równie poważnym zagrożeniem jej ekspansji. Co więcej, jest to zagrożenie, którego w krótkim okresie nie da się łatwo wyeliminować, bowiem wymagania kwalifikacyjne tej branży są dość specyficzne. Znaczna część kreatywnych zawodów wymaga od pra- 
cownika niewyuczalnego elementu talentu oraz indywidualnych, wrodzonych predyspozycji, które muszą zostać połączone z twardymi umiejętnościami i specjalistyczna wiedza, jak np. w: przemyśle filmowym, mediach, branży programistycznej, architekturze lub dziennikarstwie. Sa i takie zawody kreatywne, które nie znajduja jeszcze odpowiednich kierunków kształcenia na poziomie średnim lub wyższym 5 .

Ostatnią kwestia, która wymaga znacznego postępu, jest wprowadzenie powszechnie akceptowanych rozwiązań prawnych w zakresie praw intelektualnych, na czerpaniu, z których zysków wiele kreatywnych branż opiera swój model biznesowy. Znacząca grupa konsumentów dóbr kreatywnych są ludzie młodzi, których decyzje rynkowe w większym stopniu są uwarunkowane relatywnie niskimi dochodami. Mogą oni przedkładać niską cenę nad jakość i oryginalność, a niejednokrotnie oczekują wręcz darmowego dostępu do wytworów sektora kreatywnego. Ten nierozwiązany dylemat aksjologiczny - ochrona własności intelektualnej versus powszechny dostęp do wiedzy i kultury - nie sprzyja takiemu rozwojowi sektora, któremu towarzyszyłby wzrost liczby osób mogących utrzymać się z pracy w nim, a nie tylko tworzących kreatywne treści w ramach realizacji swoich pasji pozazawodowych.

\section{Rekomendacje związane $\mathrm{z}$ polityką $\mathrm{i}$ wspieraniem wzrostu zatrudnienia w sektorach kreatywnych}

Wskazane w powyższych rozważaniach wyzwania i zagrożenia natury ekonomicznej, społecznej i prawnej, którym sektor kreatywny musi stawić czoła dla wykorzystania swojego potencjału zatrudnieniowego, stanowia pole do uzasadnionej interwencji państwa.

Po pierwsze, wzrost zatrudnienia w sektorach kreatywnych będzie wymagał szerszego dostępu do kapitału inwestycyjnego. Aby to osiagnąć, sektor bankowy powinien nauczyć się lepiej wyceniać aktywa niematerialne, na których tworzeniu bazuje gros branż kreatywnych. Z drugiej strony, niezbędna jest promocja myślenia biznesowego w sektorach twórczych, które, do tej pory często będąc skoncentrowanymi głównie na dostarczanym produkcie lub usłudze, mniejszą wage przykładały do komercjalizacji wyników swojej pracy.

Wiele produktów sektora kreatywnego może podlegać obrotowi w formie zdygitalizowanej. Aby wykorzystać sieć do tworzenia ekonomicznej wartości dodanej, niezbędne jest jednak ciagłe inwestowanie w infrastrukturę umożliwiającą szerokopasmowy dostęp do Internetu, a także podnoszenie poziomu kształcenia twórców i konsumentów w zakresie nowożytnych języków obcych, głównie języka angielskiego.

Na szczeblu wspólnotowym i krajowym potrzebne jest rozwijanie holistycznych, międzysektorowych programów i strategii, które zapewnią możliwość rozwoju gospodarki kreatywnej. Wsparcie powinno objąć funkcjonowanie podmiotów działających w tej branży, w tym w szczególności mikro- i małych przedsiębiorstw, jak również organizacji pozarządowych. Dotyczyć ono musi nie tylko aspektów: finanso-

\footnotetext{
${ }^{5}$ Przykładem może być projektowanie gier komputerowych.
} 
wych, organizacyjnych, prawnych i promocyjnych, ale także zapewnienia odpowiednio przygotowanych pracowników. Stąd konieczne są inwestycje w nowoczesny system edukacji, rozwijanie kreatywności dzieci i młodzieży, jak również naukę i szkolnictwo wyższe w obszarach informatyki, designu, sztuki i mediów.

Wzrost zatrudnienia w sektorze kreatywnym jest współdeterminowany istnieniem popytu na jego usługi i produkty. Część przemysłów kreatywnych radzi sobie świetnie z tworzeniem zainteresowania wśród bardzo zróżnicowanego grona konsumentów (np. przemysł filmowy oraz gier komputerowych). Jednak inne wymagaja odbiorcy bardziej przygotowanego do percepcji produkcji artystycznych, który chce uczestniczyć w kulturze, jest otwarty na nowość, ceni nie tylko walory utylitarne, ale również estetyczne środowisko, w którym żyje. Wykształcenie takiego konsumenta dóbr i usług ekonomii kreatywnej wydaje się zadaniem niemożliwym do osiagnięcia bez spójnego, długofalowego wsparcia państwa, lecz kwestia ta wykracza już znacznie poza postulaty o charakterze ekonomicznym.

\section{Podsumowanie}

Kreatywna gospodarka - co potwierdzaja między innymi dotychczasowe badania australijskie, amerykańskie i brytyjskie - jest nośnikiem nie tylko potencjału tworzenia dodatkowej wartości i szybszego wzrostu PKB, ale także wielu miejsc pracy. Potrzebuje ona twórczych, dobrze wykształconych pracowników, uczy współpracy osób zróżnicowanych ze względu na wiek, płeć czy kulturę, z której się wywodzą. Daje możliwość połączenia realizacji pasji ze sposobem zapewnienia źródeł utrzymania, szansę pracy w elastycznych formach zatrudnienia i czasu pracy.

Wiele kreatywnych zawodów - co pokazano analizując zatrudnienie w krajach Unii Europejskiej - było w stanie rozwijać się także w czasie recesji i pierwszego okresu wychodzenia z dekoniunktury. Przykłady Niemiec, Wielkiej Brytanii i innych ważnych gospodarek starego kontynentu wskazują, że tempo tego wzrostu w niektórych branżach było spektakularne, kilkukrotnie przewyższyło tempo wzrostu zatrudnienia w gospodarce ogółem w tym samym okresie. Z kolei, analizy sektorowe pokazały potencjał zatrudnieniowy przede wszystkim: działalności twórczej związanej z kulturą i rozrywką oraz działalności obejmującej produkcję: filmów, nagrań wideo, programów telewizyjnych, nagrań dźwiękowych i muzycznych.

Okres stopniowego wychodzenia z recesji daje nadzieję na dalszy wzrost zatrudnienia w gospodarce kreatywnej w Europie w najbliższych latach. W artykule przedstawiono pewne cechy charakterystyczne tego sektora - zarówno strony popytowej, jak i podażowej - które bez interwencji państwa mogą stać się w przyszłości przeszkodą w stosunku do wzrostu zatrudnienia w tych branżach. Choć przywołana lista z pewnością nie wyczerpuje zbioru determinant zatrudnienia w kreatywnej gospodarce, to zwraca uwagę na pewne wyjątkowe cechy tego rynku, które - być może w większym stopniu niż w innych sektorach - uzasadniają szeroką interwencję państwa. 


\section{Literatura}

A textbook of cultural economics 2010, R. Towse (ed.), Cambridge University Press, Cambridge.

Baza danych Eurostat, dokument elektroniczny, tryb dostępu: [http://epp.eurostat.ec. europa.eu/portal/page/portal/employment_unemployment_lfs/data/database?_pi ref616_1896469_616_925165_925165.p=h\&_piref616_1896469_616_925165_925 165.expandNode=doAction\&_piref616_1896469_616_925165_925165.nextAction Id=8\&_piref616_1896469_616_925165_925165.nodePath=.EU_MAIN_TREE.da ta.popul.labour.employ.lfsa.lfsa_emp, data wejścia: 5.11.2013].

Caves R. E. 2002 Creative Industries: Contracts between Art and Commerce, Harvard University Press, Cambridge, MA.

Cultural statistics 2007, Office for Official Publications of the European Communities Luxembourg.

Cultural statistics 2011, Publications Office of the European Union, Luxembourg.

DCMS \& Creative Industries Task Force 1998 Creative Industries 1998: Mapping Documents, Department for Culture, Media and Sport, London: UK.

EESnet-CULTURE. European Statistical System Network, on Culture 2012, Final Report.

European Commission 2012 Communication From The Commission To The European Parliament, The Council, the European economic and social committee and the committee of the regions. Promoting cultural and creative sectors for growth and jobs in the EU, COM(2012) $537 \mathrm{fi}-$ nal, Brussels, 26.09.

Florida R. 2002 The Flight of the Creative Class. The New Global Competition for Talent, Harper Business, New York.

Hesmondhalgh D. 2002 The Cultural Industries, Sage, London.

Higgs P., Sunningham S. 2008 Creative Industries Mapping: Where have we come from and where are we going?, „Creative Industries Journal”, vol. 1, no 1.

Howkins J. 2002 The creative economy. How people make money from ideas, Penguin, London.

Throsby D. 2001 Economics and Culture, Cambridge University Press, Cambridge.

UNCTAD 2010 Creative Economy: A Feasible Development Option, UNCTAD, Geneva. 